\title{
Vascular Growth in the Fetal Lung
}

\author{
Stephen C. Land \\ Centre for Cardiovascular and Diabetic Medicine, \\ Division of Medical Science, Ninewells Hospital and Medical School, \\ University of Dundee, Dundee, Scotland, \\ United Kingdom
}

\section{Introduction}

The structure of the lung is truly remarkable. It is primarily composed of three branched tubular networks (the airway, pulmonary artery and vein, bronchial artery and vein) which supply blood and air to the site of gas exchange and which maintain nutrient supply to supporting tissues. This complex interwoven network is packed into a chest cavity with a volume of 6 litres but yet it services a gas-exchange surface area of $130 \mathrm{~m}^{2}$, the floor area of a comfortably sized Mediterranean holiday villa! Weibel (1991) tells us that if this surface area were arranged as a balloon it would possess a radius of $3 \mathrm{~m}$ and a volume of 113,000 litres, more than 18 thousand times the space available in the chest cavity. The process which drives this exceptional packaging involves repeated cycles of ordered branching to create a fractal network of tubules whose core dimensions decrease at a precise and regular rate with each successive branch. This is a high "gain-of-structure" process. In the airway, 23 generations of branching form a conducting tubular network with 17 million branches and a combined length of more than $7 \mathrm{~km}$. This provides convective air flow to 480 million alveoli each of which are located along a path length that is no further than $45 \mathrm{~cm}$ from the external atmosphere. The pulmonary vasculature forms along side the airway but undergoes an additional five generations of branching to form the capillary network that surrounds each alveolus. If you simply assumed that each alveolus (diameter $\sim 200 \mu \mathrm{m}$ ) was serviced by only one blood vessel you would calculate that the alveolar capillary bed alone runs to nearly $100 \mathrm{~km}$ in length. Realistic attempts at modelling this structure in three dimensions suggest that it is, in all probability, between 2 and 6 thousand $\mathrm{km}$ long (Muhlfield et al., 2010), illustrating the impressive capacity of fractal branching processes to package colossal structures into ever smaller spaces.

The airway and pulmonary vasculature interface with one another at the alveolar bloodgas barrier where oxygen and carbon dioxide diffuse along partial pressure gradients. This extremely thin $(0.65 \mu \mathrm{m})$ membrane is composed of cytoplasmic leaflets of type I alveolar epithelial cells and capillary endothelial cells held together with a chicken-wirelike mesh of type IV collagen. Here, a compromise must be met between high surface area, thin-ness and tensile strength to ensure that gas exchange proceeds efficiently from rest-to-work without rupture of the membrane caused by pressure differences across between the alveolar and vascular space. One estimate places the inherent tensile strength of this interface at $0.3 \mathrm{MPa}$ (West, 2003) which is close to that of pure type IV collagen 
(1MPa) and similar to that of building materials such ceramic fibre boards of the type often used to line an office ceiling.

From here, oxygenated blood traverses the branched venous network to the left atrium of the heart from where it is circulated around the body. The physiological outcome of this interwoven, repeated branching structure is to arrive at a balance between the need for a high gas exchange surface area and a minimal energetic cost of breathing, water and heat loss. Fractal branching achieves this by dissipating resistance to air and blood movement among the exponential rise in tubule number towards the blood-gas barrier, allowing ready passage into the recesses of the lung much like water poured into sand. Similarly, this rise in surface area ensures that inhaled air is rapidly warmed and hydrated as it passes through the upper airways so that ventilating the lung costs little in terms of heat and water loss. Thus, for most healthy people, the act of breathing when at rest or asleep is essentially subconscious and requires almost imperceptible movement of the chest to maintain convective gas exchange over the blood-gas barrier without the need for further anatomical specialisation to maintain core body temperature and hydration. Although the mammalian lung is clearly a complex organ, this is not to imply that it sits at the pinnacle of evolution amongst gas-exchange systems; in fact its structure is derived from imperfect compromise between competing selective forces and the interested reader is referred to several articles for further insight (Sander et al., 2011; West et al., 2007; Perry et al., 2001; Weibel et al., 1998; Weibel, 1984).

To generate this branched, fractal network a molecular system must be in place to programme the duration, bifurcation, orientation and damped repetition of the branching cycle. This chapter reviews the process which controls vascular growth in the lung and, in particular, how its regulation is co-ordinated with the fractal branching pattern of the airways.

\section{The pattern of vascular development in the lung}

Weibel and Gomez (1962) were among the first to document the fractal branching pattern of the airways noting that the decrease in airway diameter for each new branch declined by a constant factor ( 0.85 as re-analysed by Maury et al., 2009). The physiological outcome is to dissipate resistance to air flow which, according to Poiseuille's Law, decreases in proportion to the 4 th power of tubule diameter. Notably, the rate of decline is slightly shallower than the predicted "optimal" rate (0.79) suggesting that there is an excess of dead space within the airways. Thus, an evolutionary compromise exists between lung volume and branching which accommodates dynamic change in airway diameter caused by exercise, inflammation or disease (Maury et al., 2009).

The pulmonary vasculature closely follows the course of the conducting airways, sharing the same rate of branching and decline in diameter up to the 15th generation. Beyond this, vascular branching diverges at a greater rate proceeding through 28 generations to create the microvasculature surrounding each alveolus (Weibel, 1991). As with the airways, the net outcome is to dissipate resistance to blood flow and achieve a compact, high volume, delivery system capable of sustaining a rate of oxygen diffusion over the blood-gas barrier of $158 \mathrm{mlO}_{2} / \mathrm{min} / \mathrm{mmHg}$ (Weibel et al., 1993). The way in which this pattern of branching is co-ordinated with the growth of the airways is a question of central importance for understanding how gas exchange occurs between the blind ended airway network and the perfused circuitry of the pulmonary vasculature. 
Fetal lung development passes through five distinct stages which (in humans) proceed as: I) embryonic (26 days-6 weeks), II) pseudoglandular (6-16 weeks), III) canalicular (16-24 weeks), IV) saccular (24-36 weeks) and V) alveolar (36 weeks - 6 years of postnatal life). The canalicular stage is the first point at which the vasculature begins to form a functional interface with the airway epithelium, however, there is clear evidence that the fate of these two structures is intimately linked from the earliest stages of development. During the embryonic stage, the lung develops as a protrusion of foregut endoderm into the surrounding mesoderm tissue then bifurcates to form the left and right lung anlage. The next two rounds of branching establish the primordial lung lobes and, with them, the fundamental structure of the pulmonary vasculature.

Three models have been proposed to explain how the vasculature develops in the lung. The Vasculogenesis Model (Hall et al., 2000) proposes that the pulmonary arteries arise by continuous expansion of endothelial cell precursors (angioblasts) that fuse to form blood filled hematopoietic lakes in the mesenchyme around each airway bud. Fusion of these lakes generates a primitive vasculature which matures as the airway grows forward. This model has the advantage of simplicity as it requires only vasculogenic and fusion signals to coordinate its formation with the airway, however, it does not readily explain how ordered vascular patterns might form around each airway branch nor how these primitive vessels form junctions with existing major blood vessels. De Mello et al. (2000) proposed the Central Angiogenesis-Distal Vasculogenesis Model which suggests that the major trunks of the pulmonary artery and vein elongate through the mesenchyme surrounding the right and left lung lobes in response to an angiogenic cue generated behind each branch tip (central angiogenesis). These subsequently fuse with hematopoietic lakes around each branch tip (distal vasculogenesis) to form the basis of the pulmonary vasculature. In this model, three vascular growth cues are necessary: one to induce angiogenic growth of the major vessels along side the developing bud, the second to induce vasculogenesis around the tip of each airway branch and the third to fuse these structures together.

A problem with both of these models is that they fail to adequately explain the presence of red blood cells that appear in the vascular structures around each airway branch (Figure 1). Parera et al. (2005) examined this issue using transgenic mice bearing a vascular reporter gene (lacZ driven by the Tie2 angiopoietin receptor promoter; Tie2-LacZ). They found evidence of a continuous, perfused vascular network consisting of Tie2, PECAM-1 and Fli-1 positive endothelial cells in the mesenchyme tissue that surrounds the left and right airway branches. This network is present from the earliest stages of embryonic lung development and is derived from the heart vasculature making it inter-connected with other more distant structures such as liver and yolk sac. In their Distal Angiogenesis model, they argue that a functional vasculature extends from the heart to the distal tip region of each lung branch and that vascular growth occurs by endothelial sprouting from perfused blood vessels towards an angiogenic cue which is generated from the airway tip (the angiogenic zone; Figure 1B). Endothelial sprouts fuse with each other behind the airway bud tip so generating a perfused vascular network which surrounds each airway bud. Importantly, this occurs in three dimensions so that the angiogenic process is sustained in parallel with airway bud branching (Figure 1C). The growth of the vasculature therefore follows angiogenic cues generated by the airway which ensure that the timing and orientation of branching events is co-ordinated between these two structures at least up to the $15^{\text {th }}$ generation of airway branching. 

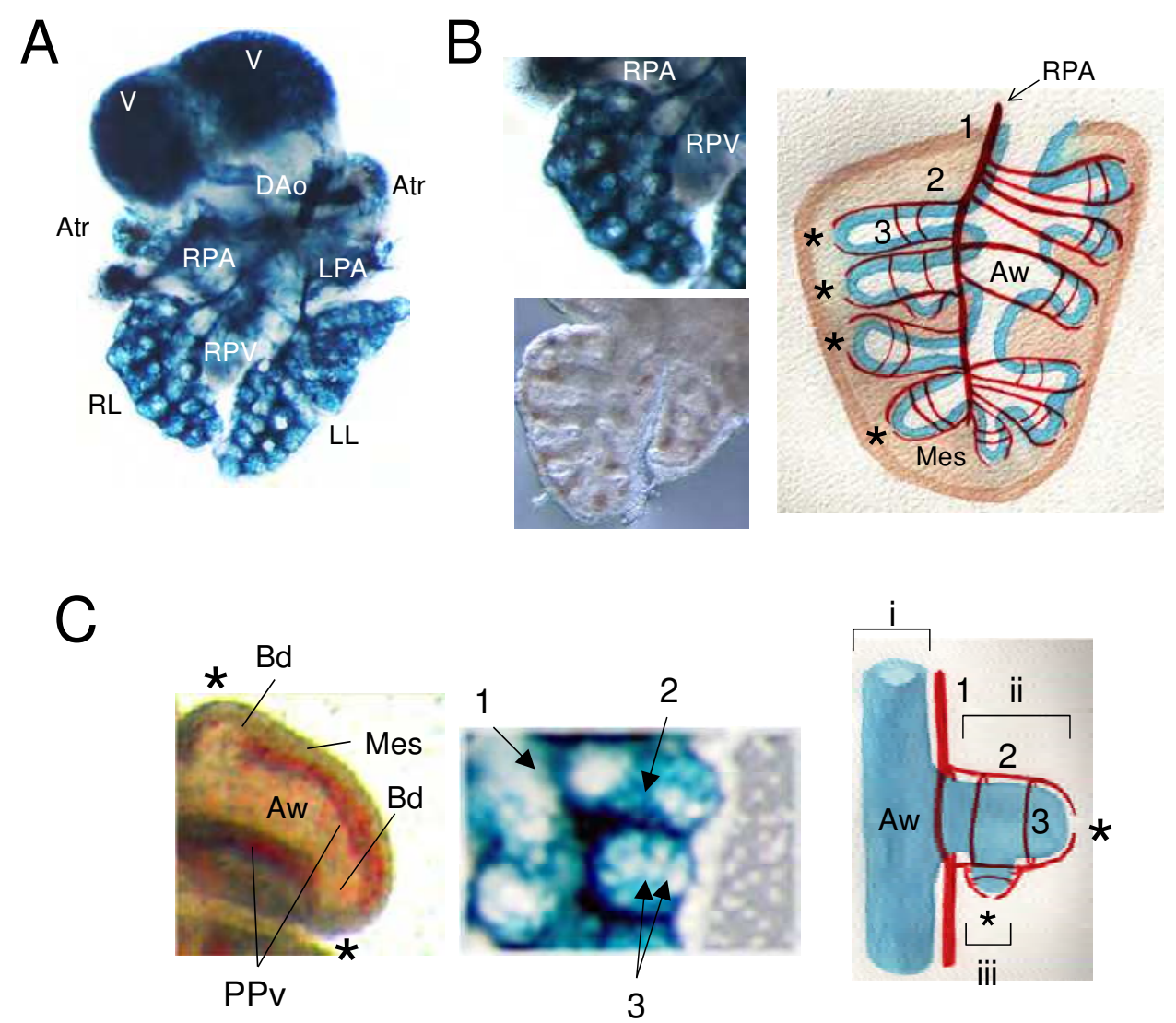

Fig. 1. Vascular growth proceeds by distal angiogenesis in the fetal lung. A. Tie2 expression (blue) in E14 fetal Tie2-LacZ mouse heart and lung. B. Detail showing Tie2 expression surrounding airway branches. Bright field image below shows airway organisation with blood-containing vessels (red hue) in the mesenchyme between each airway branch. Simplified schematic at right indicates angiogenic zone $\left(^{*}\right)$ at tip of airway with perfused vessels (3) orthogonal to the axis of the primary (1) and secondary vascular branch (2). C. Detail of vasculature around airway bud tip. Left panel: perfused vessels (red hue) can be seen in mesenchyme surrounding airway but are absent from angiogenic zone ahead of each bud tip $\left({ }^{*}\right)$. Middle panel: Tie2 positive staining marks primary (1), secondary (2) and tertiary (3) vascular branches around single buds. Right panel: Simplified schematic showing parallel branching of airway and vasculature through 3 branch generations (i-iii, airway; 1-3, vasculature). Abbreviations: Atr, atrium; Bd, airway bud; Aw, airway; Dao, dorsal aorta; Mes, mesenchyme; PPv, perfused pulmonary vasculature; RL, LL, right and left lung lobes; RPA, LPA, right and left pulmonary arteries; RPV, right pulmonary vein. $\mathrm{V}$, ventricle 


\section{Airway and vascular growth are inter-dependent processes}

Airway outgrowth is induced by secretion of fibroblast growth factor-10 (FGF-10) from discrete regions of the mesenchyme ahead of each new airway branch. As this signal encounters the airway epithelium it activates the tyrosine kinase fibroblast growth factor receptor-2b (FGFR2b) which stimulates airway tube elongation towards the FGF-10 signal (Bellusci et al., 1997). Regulated antagonism of FGF-10 expression and FGFR2b activity determines the duration of the growth stimulus and so regulates the length of each airway tube and entry into branching. A seminal study by Metzger et al. (2008) identified three different types of branching event that generate the three dimensional structure of the conducting airway: $i$ ) Domain branching, which establishes the overall shape of each lobe, ii) Planar bifurcation, which proceeds on the same plane to form branches towards the edge of each lobe and iii) Orthogonal bifurcation where branching occurs $90^{\circ}$ to the plane of growth. These branching events are governed by four pattern generating events: domain specification (the dimensions of each successive branch generation), branch periodicity generation (rate and number of branching events), bifurcation (spatial separation of branching events) and rotation (angle of branching events relative to the axis of the preceding generations). Precise timing of these events in relation to one another underpins the fractal pattern of tubular branching observed by Weibel \& Gomez (1962) for the airway and suggests that airway outgrowth and vascular development are co-ordinated through three types of branching event that is controlled by four pattern generators; but is the growth of these tubular networks inter-dependent and, if so, which regulates which?

\subsection{Linking airway and vascular growth cues}

Pattern generation in the airways is determined, in the first instance, by factors which control FGF-10 expression and FGFR2b activity. FGFR2b signaling in the airway epithelium is antagonised by Sprouty2 (Spry2) whose genomic expression and activity is induced in response to the FGF-10 signal. Once active, Spry2 suppresses the growth response to FGF-10 by blocking the formation of the protein complex which mediates guanine nucleotide signaling to the extracellular regulated kinase $1 \& 2$ (ERK1/2) pathway. The magnitude of this response is governed by the local concentration of FGF-10 around the airway bud and so determines the pattern of growth along the airway tube (Scott et al., 2010; Ramasamy et al., 2007; Tefft et al., 2002). Other ERK1/2 repressors also participate in this process to mediate close control over airway bud growth responses (eg MKP-3, Spred-1). Spry2 is therefore poised to regulate the form and magnitude of downstream signalling in response to FGF-10 and this includes influence over the activity of transcription factors which control vasculogenic signaling (discussed further in Section 4.3).

The duration of FGF-10 expression in the mesenchyme is determined by sonic hedgehog (Shh) whose expression is induced in airway epithelial cells in response to the FGF-10 signal. Secretion of Shh into the surrounding mesenchyme represses FGF-10 expression, forcing lateral movement of this growth inducing cue ahead of regions of low Shh expression. This repression of FGF-10 is locally confined by the transcription factor sine oculis-1 (Six1) and its co-activator, eyes absent-1 (Eya1), which block the expression of the Shh receptor, patched-1 (Ptc1) in the mesenchyme surrounding the airways (El-Hashash et al., 2011a,b). Thus, Six1/Eya1 and Shh form the basis of a 
regulated feedback loop which determines the spatial expression of FGF-10 in the mesenchyme.

Shh also plays a critical role in patterning the formation of other lung structures such as smooth muscle and connective tissue which develop around the airway tube as it matures (Weaver et al., 2003). It has therefore attracted much attention as a potential link between angiogenic and airway growth. Shh is known to regulate the expression of two families of angiogenic factors, the vascular endothelial growth factor-A isoforms 120, 164 and 188 $\left(\right.$ VEGF-A $\left.\mathrm{A}_{120}, 164,188\right)$ and the vessel maturation factors angiopoietin 1 and 2 (Ang1 and 2). VEGF-A is critical for fetal vascular development and knockout of its splice variant forms or its cognate receptors, VEGFR1 (Fms-related tyrosine kinase 1 (Flt1)) and VEGFR2 (synonyms: mouse: Fetal liver kinase-1 (Flk-1); human: Kinase insert Domain Receptor (KDR)), causes embryonic lethality before lung development occurs (eg Carmeliet et al., 1996; Shalaby et al; 1995; Fong et al., 1995). In the pseudoglandular-stage murine lung, VEGF- $\mathrm{A}_{120}$ and VEGF- $\mathrm{A}_{164}$ isoforms are expressed in both epithelial and mesenchymal tissue and are necessary for endothelial differentiation and angiogenesis towards the distal tip of the airway (Del Moral et al., 2006; Greenberg et al., 2002). As tubular branching progresses, this angiogenic cue becomes increasingly restricted to the distal lung epithelium where it ultimately establishes the vascular side of the blood-gas barrier throughout the canalicular to alveolar stages of development (Healy et al., 2000). This developmental restriction of VEGF- $\mathrm{A}_{164}$ expression is linked to its association with matrix components in the region of the growing bud tip and could be important for delineating different types of vascular growth response by altering the autophosphorylation pattern of VEGFR2. For example, matrix-associated VEGF-A induces distinct phosphorylation of the VEGFR2 tyrosine kinase domain which induces prolonged receptor activation, clustering and association with $\beta 1$ integrin leading to increased vascular sprouting (Chen et al., 2010; Gerhardt et al., 2003). It is interesting to speculate that this might drive the increased rate of vascular branching that occurs beyond the $15^{\text {th }}$ branch generation to create the alveolar microvasculature. Soluble VEGF-A, on the other hand, stimulates VEGFR2 association with neurolipin-1 and also receptor internalisation which is necessary for vascular maintenance, maturation of the airway epithelium and alveologenesis during the later stages of lung growth (Chen et al., 2010; Voelkel et al., 2006). In fetal lung explants, culture in the presence of soluble VEGF-A $\mathrm{A}_{164}$ induces vascular growth and endothelial cell differentiation in mesenchyme, whereas inhibition of endogenous VEGF-A $\mathrm{A}_{164}$ signaling abolishes these effects almost entirely (Zhao et al., 2005; Groenman et al., 2007). Notably, these effects are not solely confined to the vasculature but also alter airway morphogenesis. For example, soluble VEGF-A $\mathrm{A}_{164}$ augments the rate of tubule branching, however, inhibition of vascular signaling by either VEGFR2 knockdown or blockade leads to fewer branches and extensive dilation of remaining terminal airway buds (Del Moral et al., 2006; Groenman et al., 2007). Thus, VEGF-A signaling is necessary to maintain an appropriate rate of airway tubule elongation and branching but it is not an absolute requirement for airway growth as such.

So what of the role of Shh in this process? Van Tuyl et al (2007) demonstrated that knockout of Shh specifically repressed expression of Ang1, but not VEGF-A 164 nor VEGFR2 and that this suppressed both airway and vascular morphogenesis. Treatment of fetal lung explants with pro-angiogenic factors such as FGF-2 or Ang1 reinstated vascular 
growth and this was associated with a partial recovery of tubular branching suggesting that angiogenesis is necessary for airway growth to proceed. A later study showed FGF-9, not FGF-2, to be the physiological ligand which underpins this effect and reported positive synergistic FGF-9/Shh regulation of VEGF-A VI64 $_{16}$ expression which controlled the distribution of endothelial cell proliferation in the mesenchyme surrounding the developing airway bud (White et al., 2007). Subsequent vessel maturation is also Shh/Ptc dependent as knockout of either Six1/Eya1 leads to defective smooth muscle actin expression and vessel wall assembly through sustained Shh signaling to the Ptc receptor (El Hayashi et al., 2011a,b). Thus, VEGF-A signaling is critical for co-ordinated vascular and airway development and Shh appears to regulate events associated with vessel maturation as well as endothelial cell proliferation.

Shh could also influence airway growth indirectly by simply regulating the maturation rate of blood vessels. Lazarus et al. (2011) used 3D re-construction coupled with VEGFA/VEGFR2 genetic ablation to explore perfusion-independent roles of blood vessel formation in airway branching in vivo. They demonstrated that the physical absence of blood vessels, rather than the inhibition of VEGF signalling per se, has a major influence on airway branching process. They also demonstrated that vessels are required for orthogonal bifurcation events but have no effect on the planar branching process, such that blood vessel ablation leads to an overall "flat" (i.e. planar) lung morphology. This was linked to a disruption of the pattern of FGF-10 expression and de-regulation of the FGF-10/FGFR2b antagonism by Shh and Spry2. Thus, blood vessels appear to control branching patterns which specifically govern the 3-dimensional development of the conducting airways and the factors which control this process are intrinsic to the epithelium-mesenchyme-endothelium interface.

\subsection{Does the heart function influence vascular growth of the lung?}

Explant studies show that vascular growth occurs in the lung whether or not it is attached to the heart, however, distal angiogenesis ensures that there is a continuously perfused link between heart and lung so changes in heart function might also influence airway and vascular growth. This would be consistent with the role that the heart plays in determining organ placode placement, including trachea and lung, along the primitive foregut (Cardoso \& Lü, 2006) and of the vasculature in controlling orthogonal branching later in lung development (Lazarus et al.,2011). We investigated this possibility in intact fetal heart and lung explants from Tie2-LacZ mice using periodic stimulation to slow heart rate for 10 minutes at 30 minute intervals over $6 \mathrm{~h}$. Fetal lungs were then allowed to develop without stimulation for a further $24 \mathrm{~h}$ before fixing and staining for the Tie2 vascular marker (Figure 2).The results show that entrainment of pacemaker activity tends to suppress angiogenesisin the heart (seen as a reduced intensity of the blue stain) but increases airway branching frequency. Lungs grown without the heart attached, but which still received stimulation, showed no such difference in airway and vascular growth. Thus, altering patterns of heart contractility seems to disconnect the relationship between vascular growth and airway morphogenesis suggesting that changes in perfusion rate of the lung, and/or heart-derived growth factors which target airway growth, are important determinants of this relationship. This is likely to have important consequences for understanding how maternal stress and anti-depressant use influences the development of the pulmonary vasculature during pregnancy (Morrison et al., 2002). 


\section{$\underline{\text { Unpaced }}$ $\operatorname{HR}\left(22^{\circ} \mathrm{C}\right)$ \\ $=78 \mathrm{bpm}$}
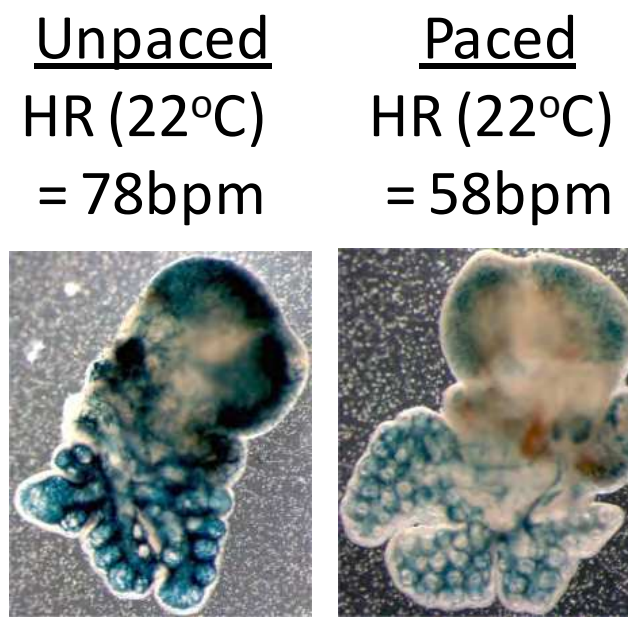

\section{$=58 \mathrm{bpm}$}
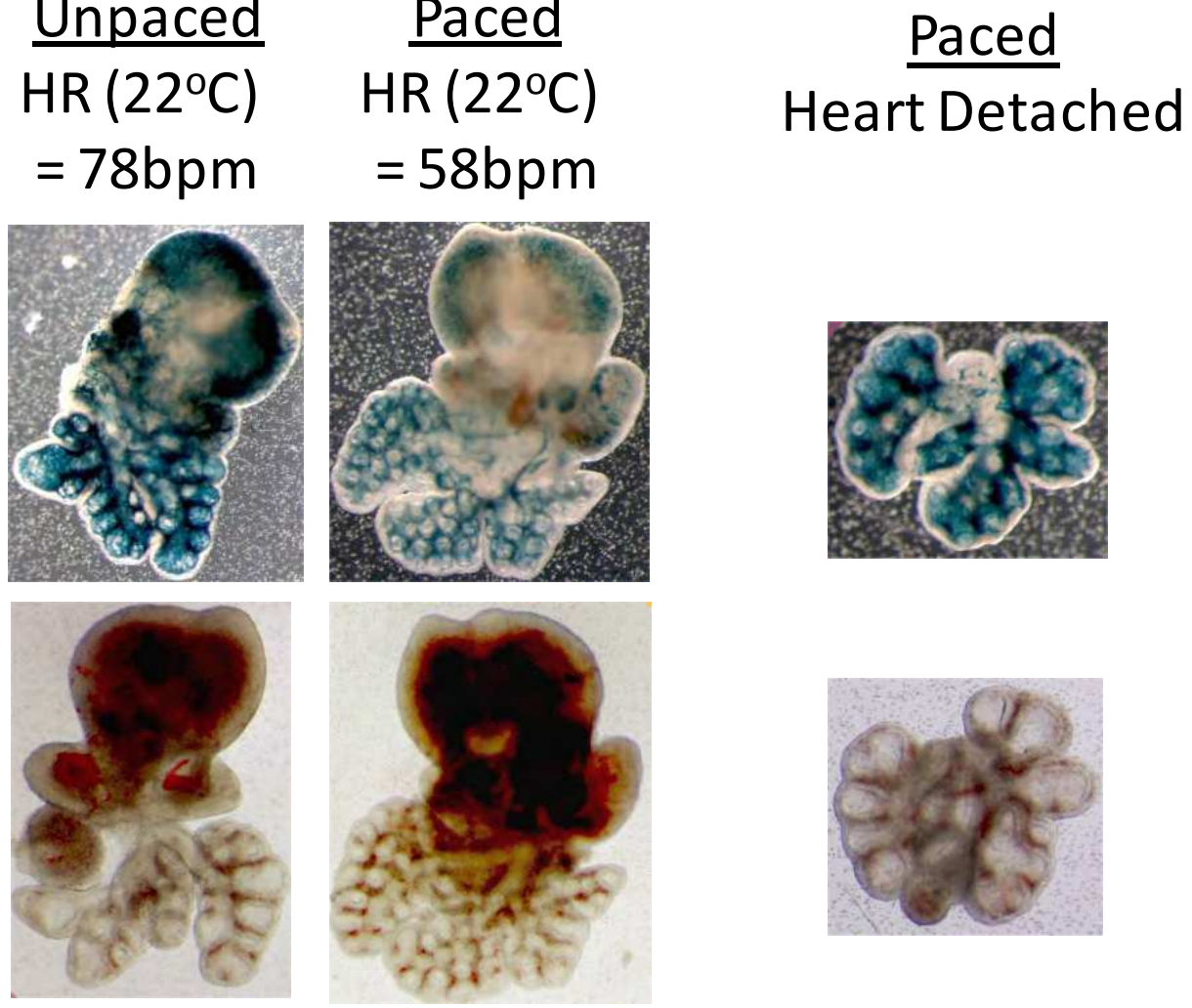

Fig. 2. Altered cardiac pacemaker activity raises airway branching rate and suppresses vascular growth. Heart and lungs from E12 Tie2-LacZ mice were excised with all connections intact and were and placed into organ culture as described by Scott et al. (2010). Pacing was achieved by stimulating preparations $(3 \mathrm{~Hz} ; 30 \mathrm{~V})$ for 10 minute intervals every 30 minutes for $6 \mathrm{~h}$ after which development was allowed to proceed normally for a further $18 \mathrm{~h}$. This produced a sustained suppression of heart rate (measured at $22^{\circ} \mathrm{C}$ ) from 78 to $58 \mathrm{bpm}$. Distribution of Tie2-lacZ expression (blue colour) as a measure of vascular growth was compared to heart-free lung preparation to which the pacing regimen had also been applied. Results shown are representative of 3 independent experiments.

\section{Regulation of VEGF-A expression in fetal airway epithelium}

Although Lazarus et al. (2011) show that the physical presence of blood vessels is necessary to drive orthogonal branching in the lung, it is clear that VEGF-A expression and secretion from the elongating airway tube is the earliest possible point of cross-talk between factors which regulate airway and vascular growth (Del Moral et al., 2006; Greenberg et al., 2002). VEGF-A gene expression is regulated at multiple levels (transcription factor binding at a 
$1.2 \mathrm{~kb}$ (mouse, rat) to $2.362 \mathrm{~kb}$ (human) $5^{\prime}$ promoter region; mRNA stability through protein interaction with its $3^{\prime}$ untranslated region; mRNA translation via IRES sequences in the $5^{\prime}$ untranslated region) and is intrinsically sensitive to external factors such as oxygen and growth factors (reviewed Pagés \& Pouyssegur, 2005). Low oxygen tensions are a persistent feature of the uterine environment, ranging from $0-13 \mathrm{mmHg}$ during embryonic implantation to $\sim 30 \mathrm{mmHg}$ throughout gestation (reviewed, Land, 2004) and raising oxygen tension beyond this range is known to inhibit vascular growth (van Tuyl et al., 2005). Given the regulated sensitivity of VEGF-A expression to hypoxia, there is therefore an appealing, if teleological, argument to suggest that oxygen availability might direct the growth and development of the gas exchange system that ensures its delivery to the mitochondrial respiratory chain.

\subsection{Hypoxia inducible factors direct vascular growth in the lung}

Oxygen-sensitive VEGF-A expression is regulated by hypoxia inducible factor (HIF) binding to a HIF consensus site (TACGTGGG) located in the 5' proximal VEGF-A promoter. HIFs are heterodimeric transcription factors comprising an oxygen regulated $\alpha$ subunit and a nuclear translocating $\beta$ subunit. In hypoxia, the $\alpha$ subunit is stabilised, dimerises with the $\beta$ subunit and is translocated to the nucleus by association with the members of the nuclear importer family, importin $\alpha 1,3,5$ or 7 (Depping et al., 2008). All three HIF $\alpha$ isoforms are expressed in the developing lung. HIF-1 $\alpha$ occurs in the branching airway epithelium and its homozygous knockout in mice causes developmental failure of the vasculature and death by E10.5 (Kotch et al., 1999). HIF-2 $\alpha$ occurs in the epithelium and interstitium and its knockout produces vascular defects during alveolar septation (Compernolle et al., 2002). HIF-3 $\alpha$ is a truncated isoform that lacks the Cterminal transactivation domain necessary for interaction with p300/CBP and so is thought to act as a competitive repressor of HIF- $1 \alpha$ and $2 \alpha$ activity (Bardos \& Ashcroft, 2005). Thus, HIF- $1 \alpha$ plays the primary role in controlling vascular signalling during lung development, whereas HIF-2 $\alpha$ function is predominantly associated with the maturation of vascular structures and the generation of the blood-gas barrier (Groenman et al., 2007). Although growth factors are well known to regulate VEGF-A expression through other transcription factors (eg Sp1, AP2; Pages \& Pouyssegur, 2005), it seems that HIF-1 $\alpha$ and $2 \alpha$-dependent regulation of vascular growth and blood vessel maturation is critical for generating the type of vascular growth, reported by Lazarus et al. (2011), that is necessary for three dimensional lung branching to occur.

HIF- $1 \alpha$ stability is regulated by $\mathrm{O}_{2}$-dependent prolyl hydroxylase proteins (PHD1,2,3) and an asparaginyl hydroxylase, factor inhibiting HIF (FIH-1). In normoxia, these enzymes utilise oxygen and the Krebs cycle intermediate, 2-oxoglutarate, to catalyse the hydroxylation of proline residues 402 and 564 in the oxygen-dependent degradation domain of HIF $\alpha$ subunits resulting in ubiquitylation by the von Hippel-Lindau E3 ubiquitin ligase (VHL) (e.g. Flashman et al., 2008). FIH-1 catalyzes the hydroxylation of asparagine 803 and blocks the interaction of the HIF transactivation domain with the CBP/p300 histone acetyltransferase. In hypoxia, the loss of oxygen and a decline in Krebs cycle activity results in PHD substrate limitation, ODD dehydroxylation, diminished VHL binding and rapid $\mathrm{HIF} \alpha$ stabilisation and transactivation. PHD substrate limitation may also be associated with the hypoxia-driven degradation of this enzyme by a different E3 ubiquitin ligase, SIAH (seven in absentia homolog) (Qi et al., 2008). PHD proteins critically regulate HIF-1-3 $\alpha$ 
stability during lung development, as their inhibition augments HIF target gene expression and promotes blood vessel growth and formation of the blood gas barrier (Asikainen et al., 2005, 2006; Groenman et al., 2007). Of the three PHD isoforms, however, PHD2 appears to exert primary regulation of HIF- $1 \alpha$ as its knockdown exclusively induces HIF-signaling activity and gene expression in normoxia, whereas knockdown of PHD1 and 3 does not (Berra et al., 2003).

Although airway and vascular development is supported better at fetal rather than postnatal $\mathrm{PO}_{2}$, and hyperoxia causes severe vascular defects which are associated with silencing of the HIF signaling system, it is unlikely that oxygen gradients direct vascular growth around the airway tip. In the fetal lung, such gradients would be shallow [ 15 mmHg $(20 \mu \mathrm{M})]$ : difference between the $\mathrm{PO}_{2}$ of the umbilical vein $(30 \mathrm{mmHg})$ and the $\mathrm{PO}_{2}$ of the amniotic fluid $\left(15 \mathrm{mmHg}\right.$; Land, 2003) and 10 -fold below the $\mathrm{Km} \mathrm{O}_{2}$ of PHD enzymes (230-250 $\mu \mathrm{M}$; Hirsilä et al., 2003). Moreover, at least in fetal pulmonary vascular smooth muscle cells, HIF-1 $\alpha$ protein stability is insensitive to oxygen tension suggesting that other modes of regulation may be more important in fetal tissues (Resnik et al., 2007). It seems more plausible that the low $\mathrm{PO}_{2}$ of the fetal environment may prime the HIF system by stabilising the $\alpha$-subunit and that local regulation is mediated by the growth factors which direct airway branching morphogenesis.

\subsection{Co-ordinating HIF activity with airway growth regulators}

In addition to its regulation by PHD proteins, HIF activity is also influenced by kinases whose signalling is controlled by tyrosine kinase growth factor receptors (Yee Koh et al., 2008) and so it is possible that HIF-directed vascular signaling could be induced from the very first interaction between FGF-10 and FGFR2b in the airway bud tip. FGF-10 activates FGFR2b by promoting receptor subunit homodimerisation which allows autophosphorylation of several tyrosine residues in its intracellular tail region (Figure 3). This promotes the binding and tyrosine phosphorylation of the lipid docking protein, suc-1associated neurotrophic factor target (FRS2 $\alpha$ ), to the active receptor complex which then recruits growth factor receptor-binding protein 2 (GRB2) and its partner, son of sevenless (Sos) (Tefft et al., 2002). Simultaneous binding of the protein tyrosine phosphatase, SHP2, to FRS2 $\alpha$ potentiates GRB2 recruitment further and establishes the overall magnitude of receptor signalling activity in response to growth factor binding (Hadari et al., 2001; Kouhara et al., 1997). Once this signaling complex is intact, GRB2/Sos catalyses the conversion of GDP to GTP on Ras, enabling the Raf serine/threonine kinase to induce MEK1 activation of the ERK1/2 signaling pathway.

FRS2 $\alpha$ can also recruit alternative adaptor proteins to induce signaling through other pathways. Tyrosine phosphorylation of FRS2a by the active FGF receptor promotes the constitutive binding of GRB2-associated binding protein 1 (GAB1) to the C-terminal SH3 domain of GRB2. This enables tyrosine phosphorylation of GAB1, which is followed by recruitment of phosphoinositide-3- kinase (PI3K) by GAB1 resulting in activation of Akt, inhibition of the tuberous sclerosis complex proteins 1 \& 2 (TSC1/2) and subsequent induction of the mammalian target of rapamycin (mTOR) signaling pathway (Eswarakumar et al., 2005). Thus, the intensity of FGF-10 interaction with its receptor can determine the magnitude and duration of signaling through a number of downstream pathways that have the potential to regulate HIF- $1 \alpha$ activity and VEGF-A expression from airway epithelium. 


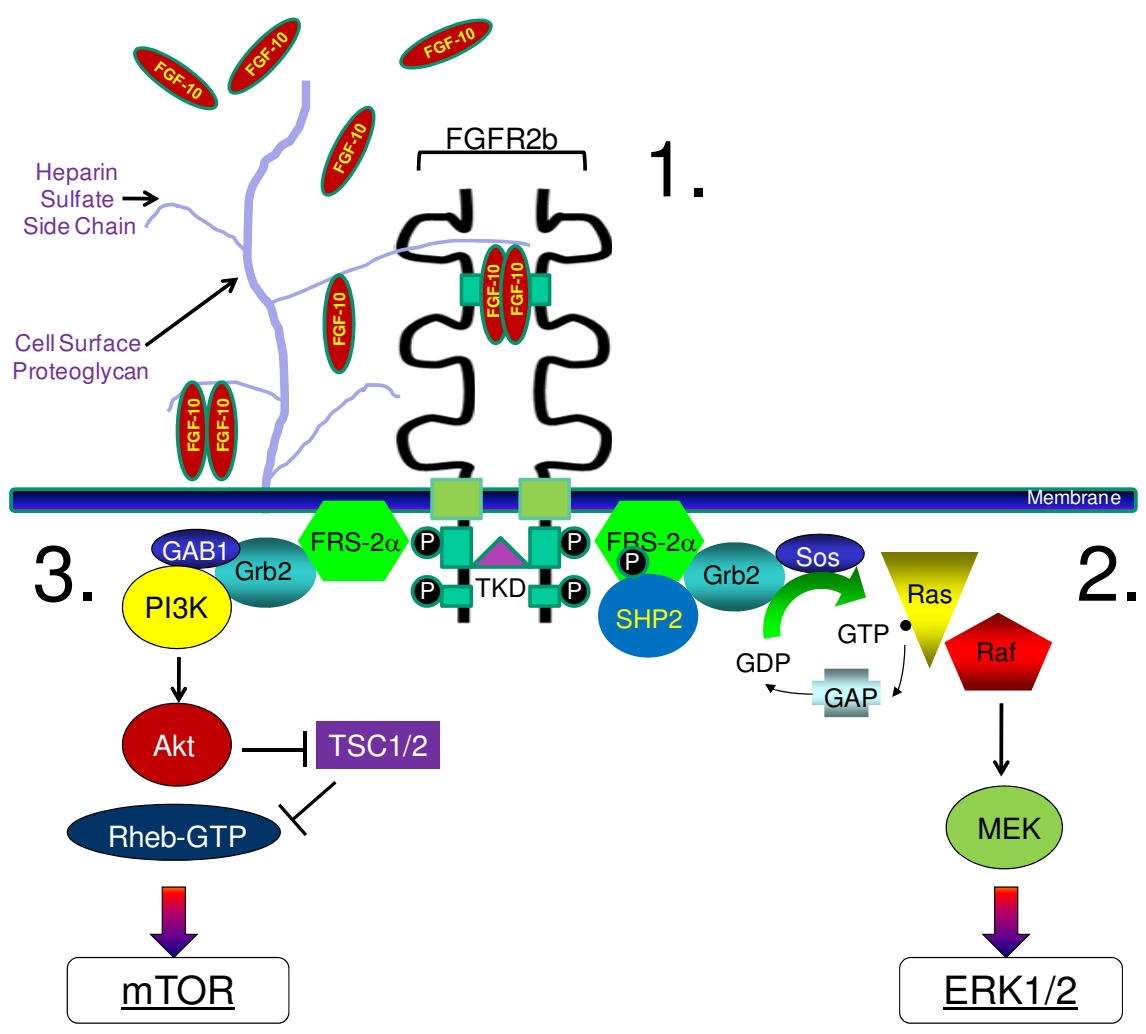

Fig. 3. FGF-10 signal transduction to the mTOR and ERK1/2 pathways. 1. FGF-10, secreted from mesenchyme ahead of the nascent airway bud, binds to heparin sulphate side chains on cell surface proteoglycans and act as a scaffold for FGFR2b homodimerisation. This induces tyrosine autophosphorylation by the active tyrosine kinase domain (TKD) which enables FRS2 $\alpha$ to bind specific phosphorylated residues and anchor a signal transduction cascade to the receptor. 2. ERK1/2 signal transduction cascade. 3. mTOR signal transduction cascade. See text for details.

Scott et al., (2010) investigated this by exposing fetal distal lung epithelial cells (FDLE) from pseudoglandular stage rat lungs to FGF-10 concentration gradients at various oxygen tensions. When cultured at alveolar $\mathrm{PO}_{2}\left(13 \% \mathrm{O}_{2}\right)$, HIF- $1 \alpha$ activity and VEGF-A secretion were unresponsive to FGF-10, however, treatment at fetal $\mathrm{PO}_{2}\left(3 \% \mathrm{O}_{2}\right)$ produced a dosedependent induction of HIF- $1 \alpha$ activity, without change in its stability, and also raised VEGF-A secretion. Both effects were matched by a sustained increase in mTOR activity and were suppressed to the endogenous level (i.e. under fetal oxygen tensions) by the mTOR inhibitor, rapamycin. Moreover, these effects were accompanied by a dose dependent inhibition of ERK1/2 and hypo-phosphorylation of the FGF receptor antagonist, Spry2, causing a band-shift to its lighter (35kDa) active form (Figure 4). Thus, it seems that FGF-10 patterns vascular signalling by favouring mTOR activity over ERK1/2 and that Spry2 may partition signaling between these kinase pathways. 


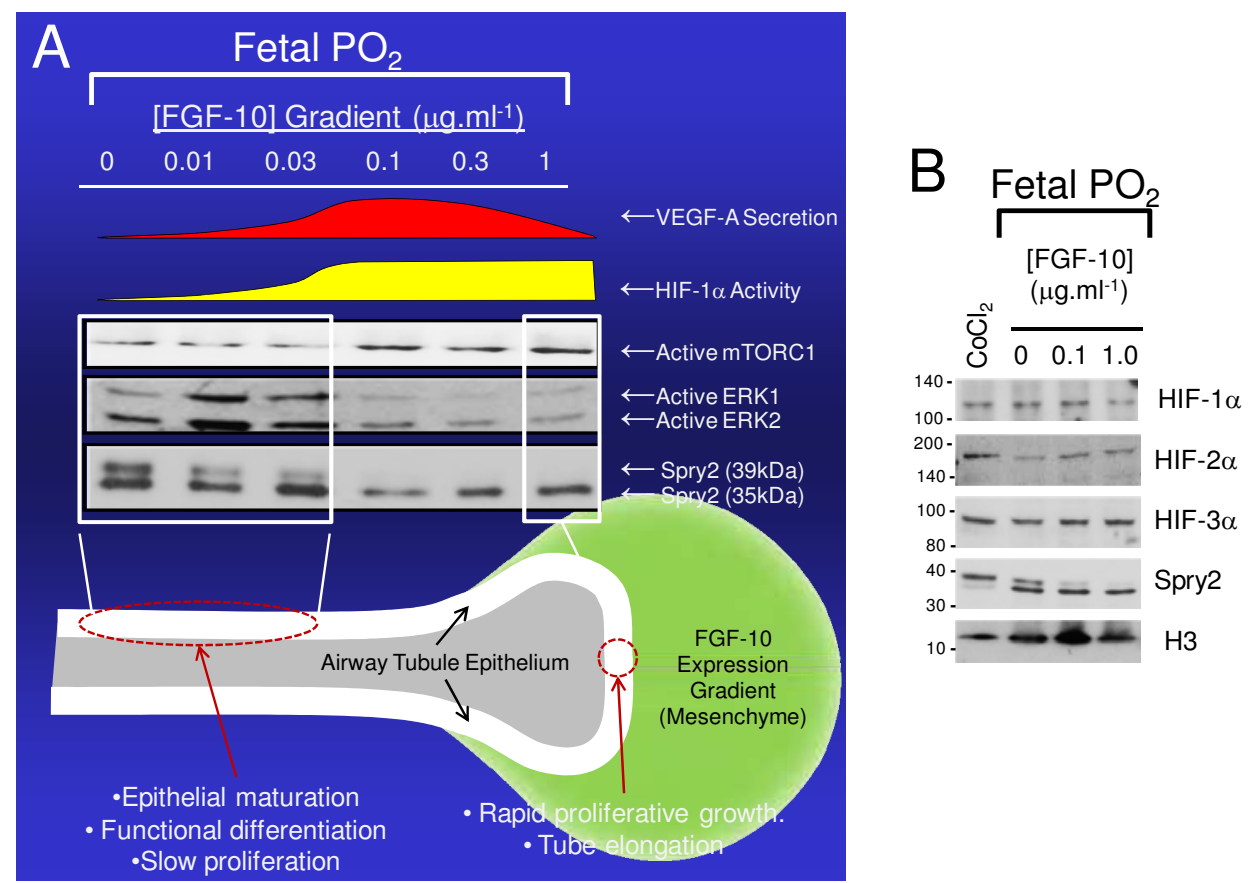

Fig. 4. FGF-10 induces vascular signaling in fetal distal lung epithelial (FDLE) cells. A. FGF-10 induces HIF-1 $\alpha$ activity and VEGF-A secretion in hand with altered mTORC-1 (S6K-phospho Thr ${ }^{389}$ ), ERK1/2 (Phospho Thr202/Tyr ${ }^{204}$ ) and Spry2 activity (see text for details) in FDLE maintained at fetal $\mathrm{PO}_{2}$. Inferred pattern of signaling within the airway tubule epithelium is shown below; data from Scott et al., (2010) B. FGF-10 does not alter HIF-1,2 or $3 \alpha$ nuclear abundance in FDLE maintained at fetal $\mathrm{PO}_{2}$. Positive control, $\mathrm{CoCl}_{2}$ $(100 \mu \mathrm{M})$.

How mTOR regulates HIF-1 $\alpha$ activity remains unclear. Although there is some evidence to suggest that this kinase can regulate HIF-1 $\alpha$ at the transcriptional level (reviewed Dunlop and Tee, 2006), there remains the exciting possibility that it may also directly interact with the HIF-1 $\alpha$ protein to co-ordinate its function with growth factor signals. mTOR forms two distinct multi protein kinase signaling complexes: mTOR complex 1 (mTORC1: mTOR, mammalian LST8/G-protein $\beta$-subunit like protein (mLST8/G $\beta$ L), PRAS40, DEPTOR and a scaffold protein known as regulatory-associated protein of mTOR (RAPTOR)) and mTOR complex 2 (mTORC2: mTOR, G $\beta$ L, mammalian stress-activated protein kinase interacting protein 1 (mSIN1) and a scaffold protein known as rapamycin-insensitive companion of mTOR (RICTOR)). The arrangement of these complexes partitions mTOR kinase activity amongst different substrates such that $\mathrm{MTORC1}$ generally links nutrient and growth factor cues to the control of translation, whereas mTORC2 links these cues to cytoskeletal proteins which control cell structure (Sarbassov et al., 2004). As mTORC2 is broadly insensitive to rapamycin, the observation that this inhibitor blocks FGF-10-evoked HIF-1 $\alpha$ activity and 
VEGF-A secretion suggests that mTORC1 drives early vascular signaling in the fetal lung. The scaffold protein RAPTOR binds this complex to its substrates by interacting with conserved penta-peptide sequences known as mTOR signaling (TOS) motifs (FDL/IDL and FEMDI within S6K1 (Schalm \& Blenis, 2002) and 4E-BP1 (Schalm et al., 2003), respectively). Mutation of the highly conserved phenylalanine at position 1 of the TOS motif prevents mTOR binding and subsequent phosphorylation of its target residues. We identified a similarly conserved TOS motif located between amino acids 99 and 104 of HIF-1 $\alpha$ (FVMVL) which was capable of binding RAPTOR and which was also necessary for growth factorsensitive regulation of HIF-1 $\alpha$ transcriptional activity (Land and Tee, 2007; Scott et al., 2010). Significantly, this interaction specifically promoted the interaction between the stable HIF$1 \alpha / \beta$ transcription factor and the $\mathrm{CBP} / \mathrm{p} 300$ histone acetyltransferase resulting in increased efficiency of HIF-regulated gene expression by elevated de-condensation of DNA from its histone complex.

The mTOR pathway plays a critical role in organ development. In mice, its expression arises at E8.5 and its inhibition, by mutation or with rapamycin, results in forebrain defects, loss of somites, poor embryonic rotation and lethality by E12.5 (Hentges et al., 2001). Ontogenic studies of mTOR function in rat fetuses show its activity is high during the early stages of development, declining towards term, but rebounds during the early neonatal period and corresponds with proportionate changes in translation efficiency during gestation and birth (Otulakowski et al, 2009; 2007). In fetal lung in vivo, phosphorylation of the mTORC-1 specific substrate, S6 kinase-1 Thr 389 , is high in the epithelium within the airway bud tip and genomic knockout of its upstream repressor, tuberous sclerosis complex-1 (TSC1), leads to gross vascular defects and widespread expression of VEGF-A in both airway and mesenchymal tissue (Scott et al., 2010). Through its interaction with HIF-1 $\alpha$, mTORC1 therefore links FGF-10/FGFR2b activity to VEGF-A secretion and vascular growth and provides a mechanism by which the growth of the fetal airway epithelium vasculature is linked from the very earliest moment of lung development.

\subsection{Linking vascular growth to the FGF-10/FGFR2b/Spry2 airway branching periodicity clock}

Although mTORC1 may link the FGF-10 signal to HIF and vascular signaling, it does not explain how branching process might occur. Sprouty proteins direct the duration and magnitude of growth factor receptor signaling and were originally described as repressors of FGF-driven tracheal branching in Drosophila (Hacohen et al., 1998). Here, tracheal branching is initiated by the protein product of the Branchless gene (Bnl) whose mammalian equivalent is FGF-10. The receptor for the branchless protein is Breathless (Btl), whose mammalian orthologue is the FGFR family. The duration of signaling between Bnl and Btl (and hence the length of tubule between each branch) is determined by Sprouty whose knockout results in accelerated tracheal branching. Sprouty proteins are therefore evolutionarily conserved, inducible inhibitors of FGF-receptor signalling which control the branching dimensions of the tracheal airway network.

In the developing lung, Sprouty proteins play a similar role to define the dimensions of the airway tree. Four sprouty isoforms (Spry 1-4) are expressed in mammals but it is Spry2 which plays the dominant role in the airway branching process, being expressed at the distal tip of the epithelial tube bud adjacent to sites of FGF-10 expression in the mesenchyme. 
Knockdown of Spry2 in fetal lung explants increases epithelial tube branching whereas its over-expression in vivo inhibits lung lobation, clefting along the periphery of the lung, failure to septate, mesenchymal thickening and an inhibition of epithelial proliferation (Mailleux et al., 2001; Tefft, et al., 1999). Later work by Metzger et al. (2008) identified Spry2 as an important regulator of airway branching whose knockout increased both branch rate the restriction of airway diameter so that distal branching patterns occurred proximally in the airway. Thus, the FGF-10/FGFR2b/Spry2 feedback loop acts as a timing mechanism which controls airway branching periodicity and so defines the fractal characteristics of the respiratory tree (Metzger et al., 2008; Warburton, 2008).

How might Spry2 co-ordinate airway and vascular branching with one another? Scott et al. (2010) showed that a rise in Spry2 activity (appearance of a hypo-phosphorylated 35kDa form) accompanies the inhibition of ERK1/2 and activation of mTORC1 that occurs in response to FGF-10, therefore, something more than FGFR inhibition must occur to produce this partitioning of kinase activity. Spry2 is well documented as an inhibitor of ERK1/2 signaling following FGF receptor activation (Figure 5). Its structure contains a conserved Nterminal tyrosine residue at position 55 (Y55) whose phosphorylation by FRS2 $\alpha$-activated Src kinase ( $\mathrm{Li}$ et al., 2004) is necessary for interaction with both protein phosphatase 2A (PP2A) and the ubiquitin ligase, cCbl (reviewed Guy et al., 2009). No single satisfactory explanation exists for what occurs next, however, it is clear that PP2A de-phosphorylates two serine residues in a serine rich region of the protein (Ser ${ }^{115}$ and Ser ${ }^{118}$ ) exposing a cryptic proline rich tail that can bind $\mathrm{SH} 3$ domain proteins and their interacting partners (Lao et al., 2007). One possibility is that Spry2 therefore acts as an adaptor protein which presents cCbl with substrates for ubiquitylation and degradation. This is supported by the observation that Grb2, a Spry2 interacting SH3 protein, can recruit the cCbl E3 ligase and its associated ubiquitination machinery into a complex with both FRS2 $\alpha$ and FGFR1, so repressing signal generation to ERK1/2 (Wong et al., 2002).

In airway epithelium, FGF-10 similarly increases Spry2 tyrosine phosphorylation (presumably at the Y55 residue), promoting its association with the FRS2 $\alpha /$ Grb2/Raf signaling complex and disrupting its formation, either by 1) targeting Grb2-associated proteins for proteasomal destruction (Guy et al., 2009; Wong et al., 2002) or 2) inter-calating into the FRS2 $\alpha /$ Grb2 signaling complex thereby disrupting downstream activation of ERK1/2 (Tefft et al., 2002). Spry2 activity is repressed by SHP2 which relieves its interaction with the Grb2 complex (possibly by dephosphorylating Y55) and whose inhibition results in sustained ERK1/2 activity (Hanafusa et al., 2004; Jarvis et al., 2006; Tefft et al., 2002). Thus, much like Sh, Spry2 forms the basis of a feedback loop which controls the duration and magnitude of the intracellular signaling response between the FGF receptor and the ERK1/2 pathway and explains the decline in ERK1/2 activity with increasing FGF-10 concentration shown in Figure 4. By implication, ERK1/2 signaling may be more important in the functional maturation of the epithelial tube behind the growing bud tip rather than in the regulation of airway outgrowth towards the FGF-10 signal.

Spry2 regulation of mTORC1 and its role in vascular signaling is less clear. mTORC-1 assembly and activation is held in check by the activity of two interacting protein partners known as Tuberous Sclerosis Complex (TSC) 1 and 2. This acts as a GTPase activating protein (GAP) towards the small G-protein known as ras homolog enriched in brain (Rheb). 


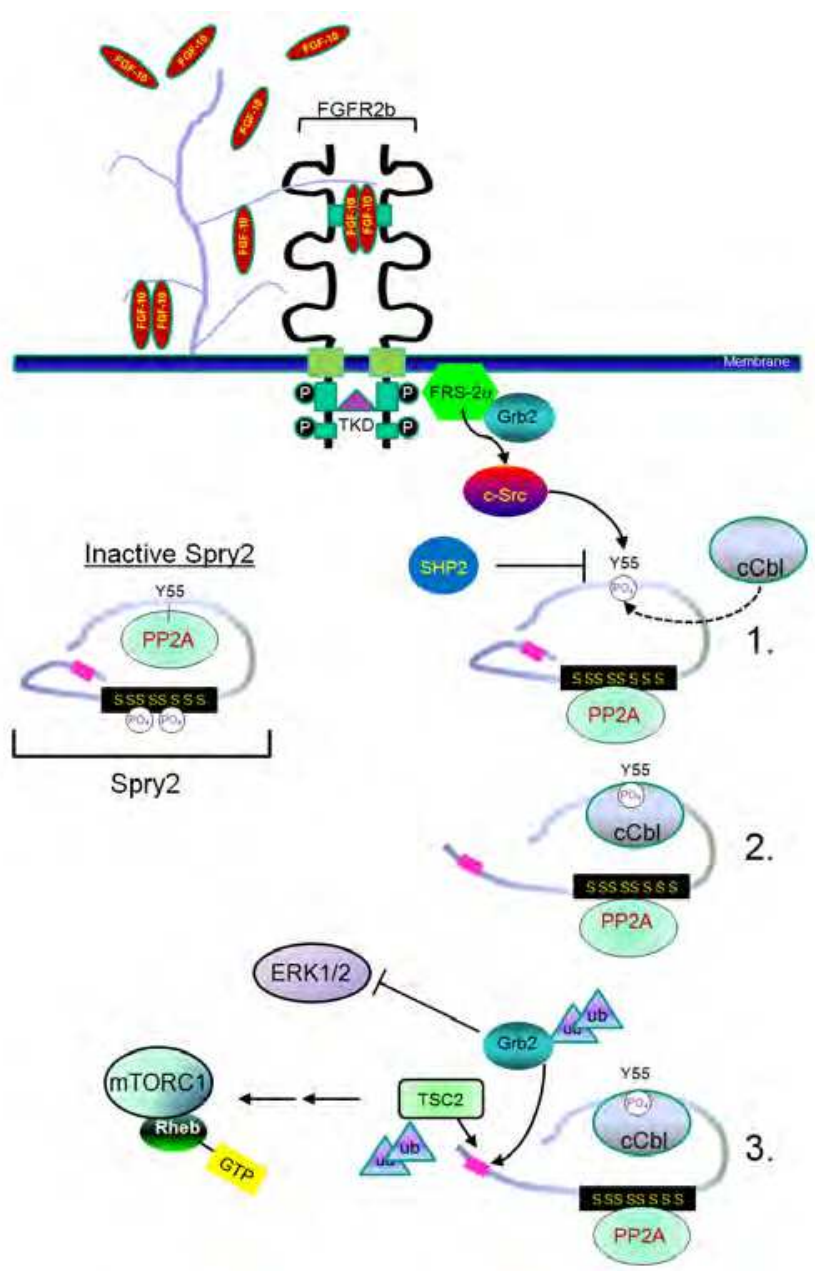

Fig. 5. Activation mechanism of Spry2. In its inactive state, Spry2 binds PP2A and is phosphorylated at serines 115 and 118. The cryptic C-terminal SH3 binding domain (magenta) is hidden within the structure of the protein. FGFR2b autophosphorylation and subsequent FRS2 $\alpha$ /Grb2 complex assembly activate Spry2 in three steps: 1 . Tyrosine phosphorylation of c-Src kinase phosphorylates the Y55 residue within the tyrosine kinase binding domain of Spry2 (antagonised by the phosphatases, SHP2). This activates protein phosphatase 2A (PP2A) enabling it to bind and dephosphorylate serines 115 and 118 within the serine rich domain (black). Phosphorylated Y55 also enables binding of the cCbl ubiquitin ligase to Spry2. 2. Dephosphorylation of the serine rich domain alters protein conformation to expose the $\mathrm{SH} 3$ protein binding region. 3. $\mathrm{SH} 3$ domain proteins such as Grb2 and, possibly, TSC2, interact with this region, becoming ubiquitylated and subsequently targeted for proteasomal clearance. Clearance of Grb2 and its associated proteins prevents ERK1/2 signaling whereas TSC2 clearance prevents GAP activity against Rheb, enabling it to bind GTP and activate mTORC1. 
When bound to GTP, Rheb potently activates mTORC1 kinase activity and this is suppressed by TSC1/2 which converts Rheb to its GDP-bound state (Zhang et al., 2003). Thus, signaling inputs into TSC1/2 that regulate its GAP activity towards Rheb are critical regulators of mTORC1 activity. Spry2 participates in this process in FGF-10-treated FDLE cells by forming a complex between TSC2 and cCbl which is associated with an increase in Rheb-GTP binding and mTORC1 activation (Figure 5; Scott et al., 2010). Although the mechanism that underpins this interaction is unclear, null mutation of the Spry2 Y55 residue produced an increase in mTORC-1 dependent HIF- $1 \alpha$ activity and VEGF-A secretion that was linked to a decline in TSC2 stability and Rheb-GAP activity (Scott et al., 2010).

Thus, Spry2 appears to direct the partitioning of kinase activity within the FGF-10 gradient where pro-vascular mTORC1 activity initiates HIF-1 $\alpha$ and VEGF-A secretion from the airway epithelium that is close to the FGF-10 source, whereas ERK1/2 activity is specifically repressed in this region. Whether this partitioning is critical for co-ordinating vascular and airway branching rate is unclear, however, it may be that Spry2-dependent control over mTORC1 governs the duration of proliferative airway and vascular outgrowth around the airway tip and that ERK1/2 activity behind this region limits this process by inducing tubular maturation towards their functionally developed forms. There is precedence for this from the stem cell literature where activation of ERK1/2 drives terminal differentiation of stem cells whereas its inhibition retains cell pleuripotency (Stavridis et al., 2010).

\subsection{An epigenetic role for Spry2 in regulating VEGF-A gene expression?}

The formation of complex, interwoven, branched tubular networks demands tight control over the timing and placement of gene expression and this is particularly important for VEGF-A where subtle changes in its abundance have major consequences for airway and vascular growth. DNA is packaged around complexes of histone proteins (octamers of histones 2A, 2B, 3 and 4) to form nucleosomes which are further organised into a helical structure to create supercoiled chromatin. Protein tails from each of the histone proteins project outwards from the nucleosome and are modified in different ways (serine phosphorylation, lysine acetylation, lysine SUMOylation, arginine methylation, ubiquitylation) to control DNA organisation. Thus, histone tail modification constitutes an epigenetic code which regulates the association of chromatin modifying proteins with DNA and the formation of active transcriptional complexes. DNA itself is also subject to modification. Methylation of cytosine residues in CG rich promoter regions (CpG islands) leads to gene repression by inhibiting the interaction of transcription complex proteins with the promoter. The three dimensional structure of chromatin enables this effect to act over long distances so that distant hypermethylated $\mathrm{CpG}$ domains (CpG shores) are capable of repressing promoter activity located $>2 \mathrm{~kb}$ downstream. The Vegfa gene promoter contains a number of CG rich stretches which have been shown to act as binding sites for Sp1 and AP-2 transcription factors (reviewed, Pagès \& Pouysségur, 2005) but probably do not act as CpG methylation islands (Kim et al., 2009). Others have shown that Vegfa can be targeted by microRNAs (miR) which either positively or negatively regulate gene expression by altering histone acetylation and the super-ordered structure of the Vegfa coding region (Turunen et al., 2009).

Given the central importance of temporal and spatial gene regulation patterns to lung development, it is reasonable to suppose that Vegfa is subject to some form of epigenetic regulation that is sensitive to FGF-10 stimulation. In non-fetal cell lines, Spry2 distribution is characteristically endosomal and migrates to the plasma membrane on tyrosine kinase receptor activation by growth factors. In FDLE, however, we have uncovered evidence that 
Spry2 also occurs in the nucleus where chromatin immunoprecipitation (ChIP) assays reveal that it interacts with the Vegfa promoter (Figure 6). Although the meaning of this interaction is currently unclear, it occurs most strongly in CG-rich regions containing the functional binding sites for Sp1 and its competitive repressor, Sp3. The interaction does not appear to be dependent upon FGF-10, however, this does not preclude FGF-10-sensitive interactions with other protein partners. Clearly, more work is needed here, however, given that Spry2 indirectly promotes the interaction between HIF- $1 \alpha$ and the CBP/p300 histone acetyltransferase (HAT), it is interesting to speculate that nuclear Spry2 may fine-tune the epigenetic regulation of the Vegfa gene by co-ordinating this effect with the recruitment of other transcriptionally active proteins to CG rich domains of the promoter. Given its role as a regulator of branching periodicity, could nuclear Spry2 act as the "clock" that regulates the timing of gene expression in response to growth factor signals?

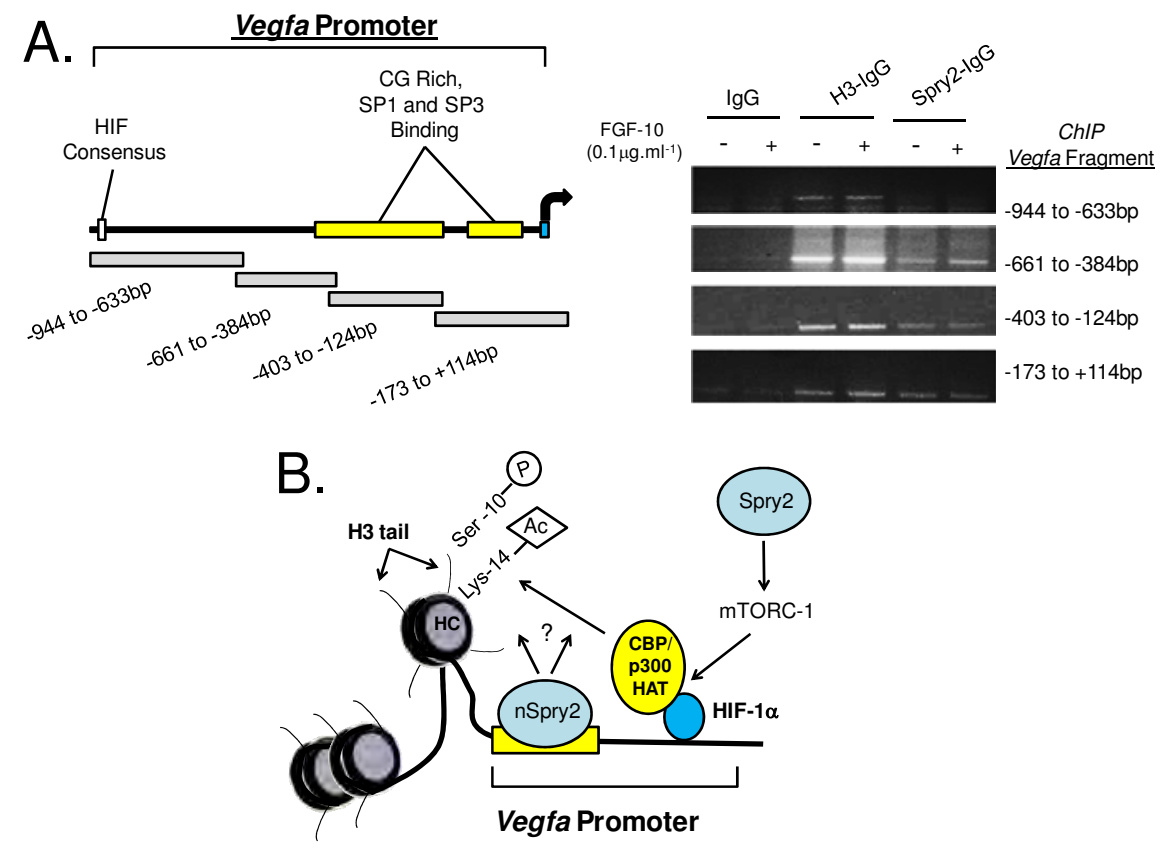

Fig. 6. Spry2 interacts with CG rich regions of the Vegfa promoter. A. Location of ChIP assay primers spanning the HIF and Sp1/3 binding sites of the Vegfa promoter. Right hand panel shows ChIP assay PCR results which reveal a constitutive interaction between Spry2 and CG-containing regions of the Vegfa promoter spanning -661 to -124 bases 5' to the transcription initiation site. IgG and Histone $3(\mathrm{H} 3)$ antibodies are negative and positive control respectively (representative of four independent assays; S.C. Land, Unpubl. Obs). B. Phosphorylation and acetylation of the $\mathrm{H} 3$ tail at Ser10 and Lys 14 promotes DNA unwinding from the histone core complex $(\mathrm{HC})$ allowing transcription to proceed. Spry2 promotes this by inducing the recruitment of $\mathrm{CBP} / \mathrm{p} 300$ to HIF-1 $\alpha$, via mTORC1. The role of nuclear Spry2 (nSpry2) in this process is speculative but may involve recruitment of other transcription factors such as Sp1 or Sp3 to the CG rich region of the Vegfa promoter. 


\section{Conclusion: Towards an integrated model of co-ordinated airway and vascular growth in the fetal lung}

The distal angiogenesis model of lung vascular development requires that there is a sustained, localized inductive cue which draws vascular growth along the airway branching path. This may be influenced by fetal heart rate which can alter both rate and intensity of airway and vascular branching. The model presented in Figure 7 suggests that the earliest pro-vascular cue is FGF-10 itself, which induces expression of VEGF-A by amplifying the HIF-1 $\alpha$ signaling pathway. This occurs by hypo-phosphorylation of Spry2 and cCbldependent inhibition of TSC 2 which enables an active MTORC1 complex to interact with the HIF-1 $\alpha$ N-terminal TOS motif. HIF-promoted VEGF-A expression occurs by enhanced $\mathrm{CBP} /$ p300 histone acetyltransferase activity binding to HIF-1 $\alpha$ which, together with Spry2 activity elsewhere in the Vegfa promoter, facilitates DNA unwinding and expression of the gene. This initial expression of VEGF-A is accompanied by directional cues which sustain vascular signaling and blood vessel maturation and also ensure that the patterning of the vasculature is confined to appropriate regions of the lung. The precise nature of these cues is unknown, however, it is reasonable to suggest that the FGF-9/Shh interaction performs this role as it does for other lung structures (smooth muscle, for example). Indeed, this interaction could be the basis of the observed need for blood vessels to grow in order to sustain the three dimensional growth of the lung.

Weibel and Gomez's original observation that the branched patterning of the airway and vasculature follows a fractal relationship from one generation to the next implies the presence of a "space and time" precision regulator which controls the rate, location and orientation of each branch process. The tight regulation of airway branching patterns in lung reported by Metzger et al. (2008) suggests that there is a hierarchy of precision regulators which control the "stop", "bifurcate", "re-orientate", "repeat" pattern of branching and that there must be some mechanism to unite these events in time along the entire branch length. The exact identity of these processes remains unknown, however, one possibility is that calcium waves which regulate smooth muscle peristalsis might serve as one periodic orientating cue which co-ordinates these events together on a grand scale (Jesudason et al., 2010). Another, is the repressive role that proteins such as Shh and Spry2 play in determining the spatial patterning and duration of FGF-10 signaling from one branch tip to another. At the molecular end of the scale, epigenetic processes determine the accessibility of RNA polymerases to DNA coding regions and so it is reasonable to expect that the dynamics of histone acetyltransferase and histone deacetylase recruitment to specific gene loci, such as Vegfa, determine, when, where and how a developmentally critical gene is expressed. This chapter ends on a speculative, but tantalising, note by suggesting that Spry2 is a good candidate for this role through its interaction with CG rich regions of the Vegfa promoter.

In the concluding chapter to his book "The Pathway for Oxygen", Weibel considers whether there is an upper limit to the design of the mammalian respiratory system by examining lung structure in the smallest mammal with the highest energetic demands, the Etruscan shrew. He reveals a lung of truly extraordinary proportions. It is ventilated at a rate of 300 breaths per minute and perfused by a heart that contracts at a rate of 17 beats per second. Volume for volume, it has a surface area that is 8-times greater than the human lung and which culminates in a blood-gas barrier which is one third the thickness. Weibel makes the point that this can only occur by taking the dimensions of all lung components to their 
extreme limit and that, in this organism, the constraints of lung design versus physiological demand cannot be pushed further. This suggests that the molecular regulation of airway and vascular development is an adaptable process that can be tuned, to a finite limit, to generate a lung that can sustain the energetic requirements of the organism. Understanding the molecular regulation of this tuning process in health and disease represents the next major goal in lung developmental biology.

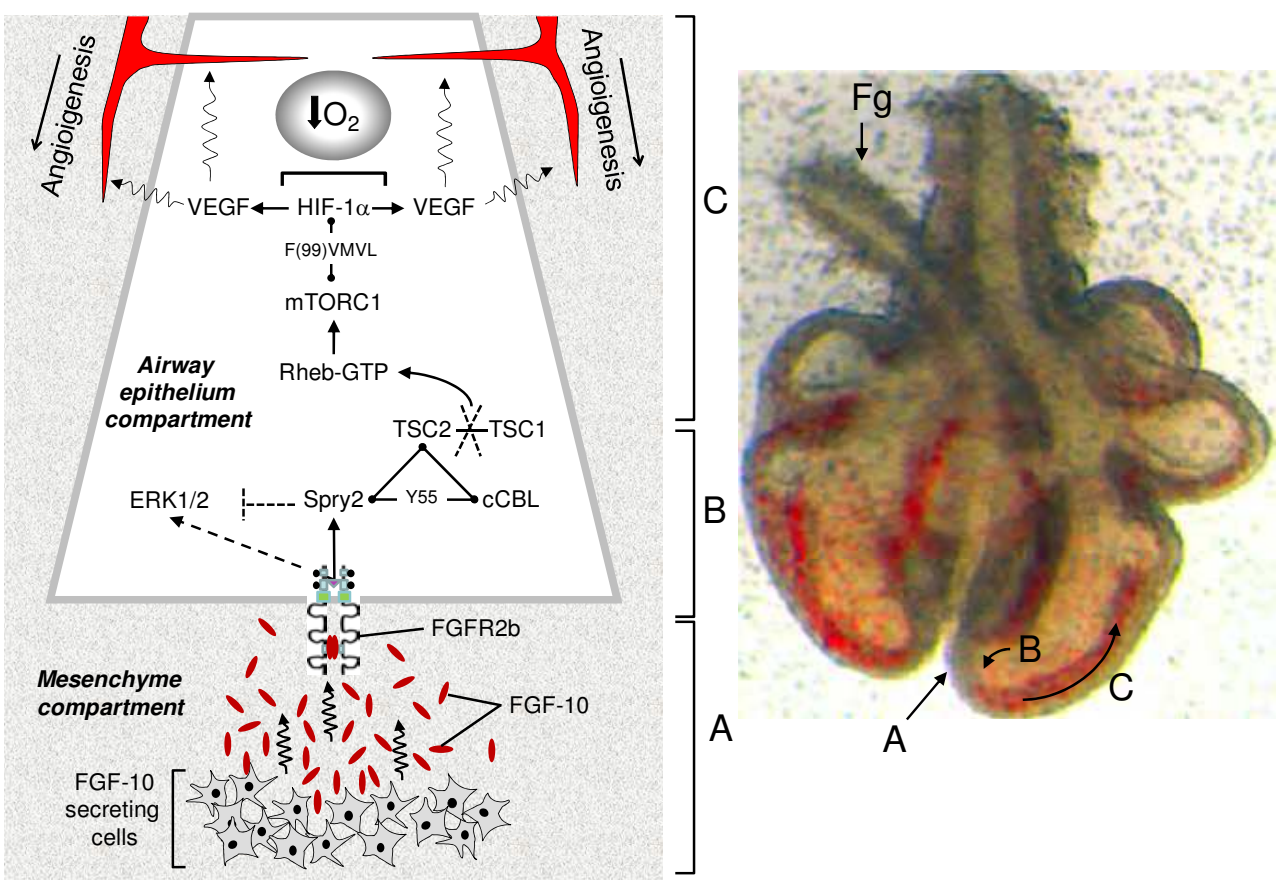

Fig. 7. FGF-10 as a co-ordinator of airway and vascular growth. Right hand panel shows an embryonic stage rat lung where perfused vasculature can be seen within the mesenchyme surrounding the airway branches and proximal to the airway tip (red hue). Foregut (Fg) is shown displaced to left of lung. Signaling in three zones of airway and vascular growth (AC) are indicated in the left hand panel. Zone A: FGF-10 is expressed in the mesenchyme ahead of nascent airway buds and diffuses towards the airway epithelium. Zone B: FGF-10 induces FGFR2b autophosphorylation and signaling to Spry2 whose activation inhibits signaling to the ERK1/2 pathway and also induces TSC2 clearance enabling Rheb to bind GTP and activate mTORC1. Zone C: mTORC1 promotes transcriptional activity of hypoxiastabilised HIF-1 $\alpha$ by interaction with its FVMVL TOS motif. This augments the expression and secretion of VEGF-A into the surrounding mesenchyme so providing the primary angiogenic cue which sustains vascular growth along with that of the airway. Figure modified from Scott et al. (2010) with permission.

\section{Acknowledgements}

Work in the author's laboratory is supported by The Wellcome Trust, UK. 


\section{References}

Asikainen TM, Chang LY, Coalson JJ, Schneider BK, Waleh NS, Ikegami M, Shannon JM, Winter VT, Grubb P, Clyman RI, Yoder BA, Crapo JD, White CW. (2006). Improved lung growth and function through hypoxia-inducible factor in primate chronic lung disease of prematurity. FASEB J Vol 20: 1698-1700.

Asikainen TM, Schneider BK, Waleh NS, Clyman RI, Ho WB, Flippin LA, Gunzler V, White CW. (2005). Activation of hypoxia-inducible factors in hyperoxia through prolyl 4hydroxylase blockade in cells and explants of primate lung. Proc Natl Acad Sci USA Vol 102: 10212-10217.

Baines DL, Ramminger SJ, Collett A, Haddad J, Best OG, Land SC, Olver RE, Wilson SM. (2001). Oxygen-evoked $\mathrm{Na}+$ transport in rat fetal distal lung epithelial cells. J Physiol. Vol 532, No 1: 105-13.

Bardos JI, Ashcroft M. (2005). Negative and positive regulation of HIF-1: a complex network. Biochim Biophys Acta Vol 1755: 107-120, 2005.

Bellusci S, Grindley SJ, Emoto H, Itoh N, Hogan BL.(1997). Fibroblast growth factor 10 (FGF10) and branching morphogenesis in the embryonic mouse lung. Development Vol 124: 4867-4878.

Berra E, Benizri E, Ginouvès A, Volmat V, Roux D, Pouysségur J. (2003) HIF prolylhydroxylase 2 is the key oxygen sensor setting low steady-state levels of HIF-1 $\alpha$ in normoxia. EMBO J Vol 22. No 16:4082-90.

Cardoso WV, Lü J. (2006) Regulation of early lung morphogenesis: questions, facts and controversies. Development. Vol 133, No9:1611-24.

Carmeliet P, Ferreira V, Breier G, Pollefeyt S, Kieckens L, Gertsenstein M, Fahrig M, Vandenhoeck A, Harpal K, Eberhardt C, Declercq C, Pawling J, Moons L, Collen D, Risau W, Nagy A. (1996). Abnormal blood vessel development and lethality in embryos lacking a single VEGF allele. Nature. Vol 380, No 6573: 435-9.

Compernolle V, Brusselmans K, Acker T, Hoet P, Tjwa M, Beck H, Plaisance S, Dor Y, Keshet E, Lupu F, Nemery B, Dewerchin M, Van Veldhoven P, Plate K, MoonsL, Collen D, Carmeliet P. (2002) Loss of HIF-2 $\alpha$ and inhibition of VEGF impair fetal lung maturation, whereas treatment with VEGF prevents fatal respiratory distress in premature mice. Nat Med.Vol 8, No 7: 702-10.

Del Moral, P. M., Sala, F. G., Tefft, D., Shi, W., Keshet, E., Bellusci, S. and Warburton, D. (2006). VEGF-A signaling through Flk-1 is a critical facilitator of early embryonic lung epithelial to endothelial crosstalk and branching morphogenesis. Dev. Biol. Vol 290:177 -188.

Depping R, Steinhoff A, Schindler SG, Friedrich B, Fagerlund R, Metzen E, Hartmann E, Köhler M. (2008). Nuclear translocation of hypoxia-inducible factors (HIFs): involvement of the classical importin alpha/beta pathway. Biochim Biophys Acta. Vol 1783, No3: 394-404.

Dunlop EA, Tee AR. (2009). Mammalian target of rapamycin complex 1: signalling inputs, substrates and feedback mechanisms. Cell Signal. Vol 21, No 6: 827-35.

El-Hashash AH, Al Alam D, Turcatel G, Bellusci S, Warburton D. (2011a). Eyes absent 1 (Eya1) is a critical coordinator of epithelial, mesenchymal and vascular morphogenesis in the mammalian lung. Dev Biol. Vol 350. No 1: 112-26. 
El-Hashash AH, Al Alam D, Turcatel G, Rogers O, Li X, Bellusci S, Warburton D. (2011b) Six 1 transcription factor is critical for coordination of epithelial, mesenchymal and vascular morphogenesis in the mammalian lung. Dev Biol. Vol 353, No 2: 242-58.

Eswarakumar VP, Lax I, Schlessinger J. (2005) Cellular signaling by fibroblast growth factor receptors. Cytokine Growth Factor Rev. Vol 16, No 2: 139-49.

Flashman E, Bagg EA, Chowdhury R, Mecinović J, Loenarz C, McDonough MA,Hewitson KS, Schofield CJ. (2008). Kinetic rationale for selectivity toward N- and C-terminal oxygen-dependent degradation domain substrates mediated by a loop region of hypoxia-inducible factor prolyl hydroxylases. J Biol Chem. Vol 283, No 7: 3808-15.

Fong, G. H., Rossant, J., Gertsenstein, M. and Breitman, M. L. (1995). Role of the Flt-1 receptor tyrosine kinase in regulating the assembly of vascular endothelium. Nature Vol 376: $66-70$.

Greenberg, F.Y. Thompson, S.K. Brooks, J.M. Shannon, K. McCormick-Shannon, J.E. Cameron, B.P. Mallory and A.L. Akeson. (2002). Mesenchymal expression of vascular endothelial growth factors $\mathrm{D}$ and $\mathrm{A}$ defines vascular patterning in developing lung, Dev. Dyn. Vol 224: 144-153.

Groenman F, Rutter M, Caniggia I, Tibboel D, Post M. (2007). Hypoxia-inducible factors in the first trimester human lung. J Histochem Cytochem. Vol 55, No 4: 355-63.

Groenman FA, Rutter M, Wang J, Caniggia I, Tibboel D, Post M. (2007). Effect of chemical stabilizers of hypoxia-inducible factors on early lung development. Am J Physiol Lung Cell Mol Physiol. Vol 293, No 3:L557-67.

Guy GR, Jackson RA, Yusoff P, Chow SY. (2009). Sprouty proteins: modified modulators, matchmakers or missing links? J Endocrinol. Vol 203, No 2: 191-202.Hadari YR, Gotoh N, Kouhara H, Lax I, Schlessinger J. (2001). Critical role for the dockingprotein FRS2 $\alpha$ in FGF receptor-mediated signal transduction pathways. Proc Natl Acad Sci U S A. Vol 98, No 15: 8578-83.

Hanafusa H, Torii S, Yasunaga T, Matsumoto K, Nishida E. (2004) Shp2, and SH2-containing protein-tyrosine phosphatase, positively regulates receptor tyrosine signaling by dephosphorylating and inactivating the inhibitor Sprouty. J. Bio. Chem. Vol 279: 22992-22995.

Healy AM, Morgenthau L, Zhu X, Farber HW, Cardoso WV. (2000). VEGF is deposited in the subepithelial matrix at the leading edge of branching airways and stimulates neovascularization in the murine embryonic lung. Dev Dyn. 2000 Vol 219 No 3:3 41-52.

Hentges KE, Sirry B, Gingeras AC, Sarbassov D, Sonenberg N, Sabatini D, Peterson AS. (2001). FRAP/mTOR is required for proliferation and patterning during embryonic development in the mouse. Proc Natl Acad Sci USA Vol 98: 13796-13801, 2001.

Hirsilä M, Koivunen P, Günzler V, Kivirikko KI, Myllyharju J. (2003). Characterization of the human prolyl 4-hydroxylases that modify the hypoxia-inducible factor. J Biol Chem Vol 278: 30772-30780.

Jarvis LA, Toering SJ, Simon MA, Krasnow MA, Smith-Bolton RK. (2006). Sprouty proteins are in vivo targets of Corkscrew/SHP-2 tyrosine phosphatases. Development Vol 133: 1133-1142.

Jesudason EC, Keshet E, Warburton D. (2010). Entrained pulmonary clocks: epithelium and vasculature keeping pace. Am J Physiol Lung Cell Mol Physiol. Vol 299, No 4: L453-4. 
Kim JY, Hwang JH, Zhou W, Shin J, Noh SM, Song IS, Kim JY, Lee SH, Kim J. (2009). The expression of VEGF receptor genes is concurrently influenced by epigenetic gene silencing of the genes and VEGF activation. Epigenetics. Vol 4 No 5: 13-21.

Kouhara H, Hadari YR, Spivak-Kroizman T, Schilling J, Bar-Sagi D, Lax I, Schlessinger J. (1997). A lipid-anchored Grb2-binding protein that links FGF-receptor activation to the Ras/MAPK signaling pathway. Cell. Vol 89, No 5: 693-702.

Land, SC.(2004). Hochachka's "Hypoxia Defense Strategies" and the development of the pathway for oxygen. Comp Biochem. Physiol. B Vol 139: 415-433.

Land SC. (2003). Oxygen-sensing pathways and the development of mammalian gas exchange. Redox Report Vol 8: 326-340.

Land SC, Collett A.(2001) Detection of $\mathrm{Cl}^{-}$flux in the apical microenvironment of cultured foetal distal lung epithelial cells. J Exp Biol. Vol 204, No 4: 785-95.

Lao DH, Yusoff P, Chandramouli S, Philp RJ, Fong CW, Jackson RA, Saw TY, Yu CY \& Guy GR (2007) Direct binding of PP2A to Sprouty2 and phosphorylation changes are a prerequisite for ERK inhibition downstream of fibroblast growth factor receptor stimulation. J. Biol Chem. Vol 282: 9117-9126.

Lazarus A, Del-Moral PM, Ilovich O, Mishani E, Warburton D, Keshet E. (2011). A perfusion-independent role of blood vessels in determining branching stereotypy of lung airways. Development. Vol 138 No 11: 2359-68.

Li X, Brunton VG, Burgar HR, Wheldon LM, Heath JK. (2004). FRS2-dependent SrC activation is required for fibroblast growth factor receptor-induced phosphorylation of Sprouty and Suppression of ERK activity. J. Cell Sci Vol 117: 6007-6017.

Mailleux AA, Tefft D, Ndiaye D, Itoh N, Thiery JP, Warburton D, Bellusci S. (2001). Evidence that SPROUTY2 functions as an inhibitor of mouse embryonic lung growth and morphogenesis. Mech Dev. Vol102, Nos 1-2: 81-94.

Mauroy B, Filoche M, Weibel ER, Sapoval B. (2004). An optimal bronchial tree may be dangerous. Nature. Vol $427: 633-6$.

Metzger RJ, Klein OD, Martin GR, Krasnow MA. (2008). The branching programme of mouse lung development. Nature. Vol 453:745-50.

Morrison JL, Chien C, Riggs KW, Gruber N, Rurak D. (2002). Effect of maternal fluoxetine administration on uterine blood flow, fetal blood gas status, and growth. Pediatr Res. Vol 51 No4: 433-42.

Mühlfeld C, Weibel ER, Hahn U, Kummer W, Nyengaard JR, Ochs M. (2010). Is length an appropriate estimator to characterize pulmonary alveolar capillaries? A critical evaluation in the human lung. Anat Rec (Hoboken). Vol 293 No 7: 1270-5.

Ng YS, R. Rohan, M.E. Sunday, D.E. Demello and P.A. D'Amore (2001) Differential expression of VEGF isoforms in mouse during development and in the adult, Dev. Dyn. Vol 220: 112-121.

Otulakowski G, Duan W, O’Brodovich H.(2009). Global and gene-specific translational regulation in rat lung development. Am J Respir Cell Mol Biol Vol 40: 555-567.

Otulakowski G, Duan W, Gandhi S, O'brodovich H.(2007). Steroid and oxygen effects on eIF4F complex, mTOR, and ENaC translation in fetal lung epithelia. Am J Respir Cell Mol Biol. Vol 37, No 4: 457-66.

Pagès G, Pouysségur J. (2005).Transcriptional regulation of the Vascular Endothelial Growth Factor gene-a concert of activating factors. Cardiovasc Res. Vol 65 No3: 564-73. 
Perry SF, Wilson RJ, Straus C, Harris MB, Remmers JE. (2001). Which came first, the lung or the breath? Comp Biochem Physiol A Mol Integr Physiol. Vol 129 No 1: 37-47.

Qi J, Nakayama K, Gaitonde S, Goydos JS, Krajewski S, Eroshkin A, Bar-Sagi D, Bowtell D, Ronai Z. (2008). The ubiquitin ligase Siah2 regulates tumorigenesis and metastasis by HIF-dependent and -independent pathways. Proc Natl Acad Sci USA Vol 105: 16713-16718.

Ramasamy SK, Mailleux AA, Gupte VV, Mata F, Sala FG, Veltmaat JM, Del Moral PM, De Langhe S, Parsa S, Kelly LK, Kelly R, Shia W, Keshet E, Minoo P, Warburton D, Bellusci S. (2007). Fgf10 dosage is critical for the amplification of epithelial cell progenitors and for the formation of multiple mesenchymal lineages durin $g$ lung development. Dev Biol. Vol 307, No 2: 237-47.

Resnik ER, Herron JM, Lyu SC, Cornfield DN. (2007). Developmental regulation of hypoxiainducible factor 1 and prolyl-hydroxylases in pulmonary vascular smooth muscle cells. Proc Natl Acad Sci U S A. Vol 104 No 47: 18789-94.

Sander PM, Christian A, Clauss M, Fechner R, Gee CT, Griebeler EM, Gunga HC,Hummel J, Mallison H, Perry SF, Preuschoft H, Rauhut OW, Remes K, Tütken T, Wings O, Witzel U. (2011) Biology of the sauropod dinosaurs: the evolution of gigantism. Biol Rev Camb Philos Soc. Vol 86 No 1: 117-55.

Sarbassov D, Ali S, Kim D, Guertin D, Latek R, Erdjument-Bromage H, Tempst P, Sabatini D (2004). Rictor, a novel binding partner of $\mathrm{mTOR}$, defines a rapamycin-insensitive and raptor-independent pathway that regulates the cytoskeleton. Curr Biol Vol 14, No $14: 1296-302$.

Schalm SS, Blenis J. (2002). Identification of a conserved motif required for mTOR signaling. Curr Biol. Vol 12, No 8: 632-9.

Schalm SS, Fingar DC, Sabatini DM, Blenis J. (2003). TOS motif-mediated raptor binding regulates 4E-BP1 multisite phosphorylation and function. Curr Biol. Vol 13, No 10: 797-806.

Scott CL, Walker DJ, Cwiklinski E, Tait C, Tee AR, Land SC. (2010). Control of HIF-1 $\alpha$ and vascular signaling in fetal lung involves cross talk between mTORC1 and the FGF10/FGFR2b/Spry2 airway branching periodicity clock. Am J Physiol Lung Cell Mol Physiol. Vol 299 No 4: L455-71.

Shalaby, F., Rossant, J., Yamaguchi, T. P., Gertsenstein, M., Wu, X. F., Breitman, M. L. and Schuh, A. C. (1995). Failure of blood-island formation and vasculogenesis in Flk-1deficient mice. Nature Vol 376: 62 -66.

Stavridis MP, Collins BJ, Storey KG. (2010). Retinoic acid orchestrates fibroblast growth factor signalling to drive embryonic stem cell differentiation. Development Vol 137: 881-890.

Tefft D, Lee M, Smith S, Crowe DL, Bellusci S, Warburton D. (2002) mSprouty2 inhibits FGF10-activated MAP kinase by differentially binding to upstream target proteins. Am J Physiol Lung Cell Mol Physiol Vol 283: L700-L706.

Tefft D, Lee M, Smith S, Leinwand M, Zhao J, Bringas P Jr, Crowe DL, Warburton D (1999). Conserved function of mSpry-2, a murine homolog of Drosophila sprouty, which negatively modulates respiratory organogenesis. Curr Biol. Vol 9. No 4 :219-22.

Turunen MP, Lehtola T, Heinonen SE, Assefa GS, Korpisalo P, Girnary R, Glass CK, Väisänen S, Ylä-Herttuala S. (2009). Efficient regulation of VEGF expression by 
promoter-targeted lentiviral shRNAs based on epigenetic mechanism: a novel example of epigenetherapy. Circ Res. Vol 105 No 6: 604-9.

van Tuyl M, Groenman F, Wang J, Kuliszewski M, Liu J, Tibboel D, Post M. (2007). Angiogenic factors stimulate tubular branching morphogenesis of sonic hedgehogdeficient lungs. Dev Biol. Vol 303, No 2 :514-26.

van Tuyl M, Liu J, Wang J, Kuliszewski M, Tibboel D, Post M. (2005). Role of oxygen and vascular development in epithelial branching morphogenesis of the developing mouse lung. Am J Physiol Lung Cell Mol Physiol Vol 288: L167-L178.

Warburton D. (2008). Developmental biology: order in the lung. Nature Vol 453: 733-735.

Weaver M, Batts L, Hogan BL. (2003). Tissue interactions pattern the mesenchyme of the embryonic mouse lung. Dev Biol. Vol 258, No 1 :169-84.

Weibel ER, Taylor, CR and L Bolis. (1998). Principles of Animal Design, Cambridge University Press, 315pp.

Weibel ER, Federspiel WJ, Fryder-Doffey F, Hsia CCW, König M, Stalder-Navarro V, Vock R. (1993). Morphometric model for pulmonary diffusing capacity. I. Membrane diffusing capacity. Respir Physiol. Vol 93: 125-49.

Weibel ER. (1991). Fractal Geometry: a design principle for living organisms. Am. J. Physiol. Lung Cell Mol. Physiol. Vol 261 No. 5: L361-L369.

Weibel ER (1984). The Pathway for Oxygen. Harvard University Press, 425pp

Weibel ER, and Gomez DM. (1962). Architecture of the human lung. Use of quantitative methods establishes fundamental relations between size and number of lung structures. Science Vol 137: 577-585.

West BJ, Bhargava V, and Goldberger AL. (1986). Beyond the principle of similitude: renormalization in the bronchial tree. J Appl Physiol Vol 60: 1089-1097.

West JB, Watson RR, Fu Z. (2007). The human lung: did evolution get it wrong? Eur Respir J. Vol 29 No 1: 11-7.

West JB. (2003). Thoughts on the pulmonary blood-gas barrier. Am J Physiol Lung Cell Mol Physiol. Vol 285 No 3: L501-13.

White AC, Lavine KJ, Ornitz DM. (2007). FGF9 and SHH regulate mesenchymal Vegfa expression and development of the pulmonary capillary network. Development. Vol 134, No 20: 3743-52.

Wong A, Lamothe B, Lee A, Schlessinger J \& Lax I (2002) FRS2 $\alpha$ attenuates FGF receptor signaling by Grb2-mediated recruitment of the ubiquitin ligase Cbl. Proc Natl. Acad. Sci. USA Vol 99: 6684-6689.

Yee Koh M, Spivak-Kroizman TR, Powis G. (2008). HIF-1 regulation: not so easy come, easy go. Trends Biochem Sci. Vol 33, No 11: 526-34.

Zhang Y, Gao X, Saucedo LJ, Ru B, Edgar BA, Pan D. (2003). Rheb is a direct target of the tuberous sclerosis tumour suppressor proteins. Nat Cell Biol. Vol 5 No 6: 578-81.

Zhao, L., Wang, K., Ferrara, N. and Vu, T. H. (2005). Vascular endothelial growth factor coordinates proper development of lung epithelium and vasculature. Mech. Dev. Vol 122: $877-886$. 


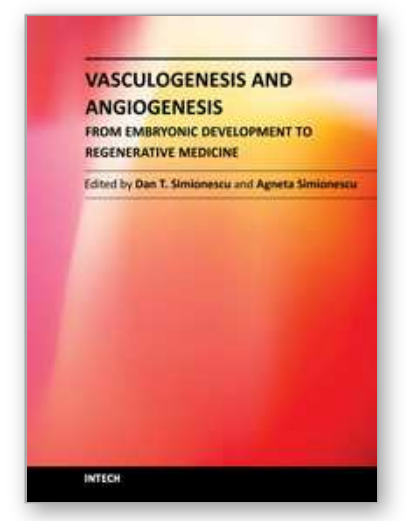

\author{
Vasculogenesis and Angiogenesis - from Embryonic Development \\ to Regenerative Medicine \\ Edited by Dr. Dan Simionescu
}

ISBN 978-953-307-882-3

Hard cover, 226 pages

Publisher InTech

Published online 07, November, 2011

Published in print edition November, 2011

Vasculogenesis is the process of new blood vessel formation during embryonic development of the cardiovascular system. This is followed by formation of a vascular tree and finally the cardiovascular system with the myriad of blood vessels that nourish all tissues and organs. Angiogenesis, on the other hand is the process by which new blood vessels take shape from existing blood vessels by "sprouting" of endothelial cells thus expanding the vascular tree. Both scenarios are based on activation, migration, proliferation and maturation of unique precursor cells. The study of blood vessel formation is an essential component of embryonic development, congenital malformations, degenerative diseases, inflammation and cancer and thus has widespread appeal to the biomedical field. Moreover, scientists are now harnessing this information for the purpose of building living blood vessel substitutes for replacement of diseased arteries and veins. This book highlights novel advances in the field of vasculogenesis and angiogenesis, including embryogenesis and development, regulation of progenitor cells, cancer and blood vessel regeneration. We consider this book a good initial source of information for graduate students, medical students and scientists interested in the intricacies of blood vessel formation, maturation, disease and replacement.

\title{
How to reference
}

In order to correctly reference this scholarly work, feel free to copy and paste the following:

Stephen C. Land (2011). Vascular Growth in the Fetal Lung, Vasculogenesis and Angiogenesis - from Embryonic Development to Regenerative Medicine, Dr. Dan Simionescu (Ed.), ISBN: 978-953-307-882-3, InTech, Available from: http://www.intechopen.com/books/vasculogenesis-and-angiogenesis-from-embryonicdevelopment-to-regenerative-medicine/vascular-growth-in-the-fetal-lung

\section{INTECH}

open science | open minds

\section{InTech Europe}

University Campus STeP Ri

Slavka Krautzeka 83/A

51000 Rijeka, Croatia

Phone: +385 (51) 770447

Fax: +385 (51) 686166

www.intechopen.com

\section{InTech China}

Unit 405, Office Block, Hotel Equatorial Shanghai

No.65, Yan An Road (West), Shanghai, 200040, China

中国上海市延安西路 65 号上海国际贵都大饭店办公楼 405 单元

Phone: +86-21-62489820

Fax: +86-21-62489821 
(C) 2011 The Author(s). Licensee IntechOpen. This is an open access article distributed under the terms of the Creative Commons Attribution 3.0 License, which permits unrestricted use, distribution, and reproduction in any medium, provided the original work is properly cited. 